\title{
Pet birds as an independent risk factor for lung cancer: case-control study
}

\author{
L Kohlmeier, G Arminger, S Bartolomeycik, B Bellach, J Rehm, M Thamm
}

\begin{abstract}
Objective-To test the hypothesis that exposure to pet birds increases risk of developing lung cancer.

Design-Case-control study. Computerised interviews were used to assess previous exposure to pets and other risk factors for lung cancer.

Setting-Three major hospitals treating respiratory disease in former West Berlin.

Subjects-All people newly diagnosed as having primary malignant neoplasm of the trachea, bronchi, or lung who were 65 or younger and control subjects matched for age and sex from the general population of former West Berlin. 279 cases and 635 controls qualified for the study; 239 cases and 429 controls participated.
\end{abstract}

Main outcome measures-Odds ratio of developing lung cancer according to whether or not pet birds were kept and the duration of keeping pet birds.

Results-In addition to the risk of lung cancer imposed by smoking, passive smoking, and occupational exposure to carcinogens, an increased relative risk of $2 \cdot 14(95 \%$ confidence interval $1 \cdot 35$ to $3 \cdot 40)$ was found among people exposed to pet birds. The adjusted odds ratio for exposures longer than 10 years was $3 \cdot 19(1 \cdot 48$ to $8 \cdot 21)$.

Conclusions-Avian exposure seems to carry a risk of lung cancer. Until the pathogenesis is understood, long term exposure to pet birds in living areas should be avoided, especially among people at high risk of developing lung cancer.

\section{Introduction}

The cause of a considerable amount of lung cancer in the Western world remains unexplained by cigarette smoking alone.' In some countries the rate of lung cancer unrelated to tobacco use seems to be increasing. ${ }^{2}$ Among the hypotheses to explain the remaining proportion are radon exposure, ${ }^{3}$ passive smoking, and occupational exposure to lung carcinogens. In addition, exposure to pet birds may also increase the risk of lung cancer.

Contact with birds has been associated with impaired pulmonary function, including chronic avian hypersensitivity pneumonitis or extrinsic allergic alveolitis. ${ }^{8-13}$ The result can be pulmonary interstitial fibrosis and permanent pulmonary impairment. ${ }^{14 !}$

Long term exposure to avian antigens has resulted in reduced $T$ suppressor cell activity in lymphocytes obtained by lavage. is Parasites such as Sarcocystis falcutula, carried by canaries and pigeons, are known to affect the pulmonary epithelial cells of the birds themselves. ${ }^{10}$

Non-smoking pigeon fanciers maintain high concentrations of $\operatorname{IgG}$ antibody to pigeon $\gamma$ globulin and increased rates of clearance of diethylenetriaminepentaacetic acid labelled with technetium-99m, which indicate that the lungs' integrity is affected. ${ }^{20}$ Whether such changes initiate the development of cancerogenic cells has not been investigated in humans.

To examine the hypothesis of a relation between household exposure to pet birds and the risk of developing lung cancer in smokers and non-smokers we conducted a case-control study in former West Berlin. In addition to previous exposure to household pets we assessed other known and suspected influences on the risk of developing lung cancer such as diet, a history of smoking and passive smoking, and occupational exposure to lung carcinogens.

\section{Subjects and methods}

CASE ASCERTAINMENT

Cases were recruited from the three hospitals in former West Berlin where around half of all patients with lung cancer were treated. The recruitment period was from April to October 1990. The selection criteria for cases were age not exceeding 65 years; a confirmed diagnosis of primary malignant neoplasm of the trachea, bronchi, or lung (International Classification of Diseases 162 (ninth revision).) $)^{21}$ during the two years before the interview; and German citizenship. Sixty five $(27 \%)$ of the 239 cases were recruited from the post-cancer clinic of one of the participating hospitals. In these patients disease was diagnosed on average during the year before the interview. The 174 other $(73 \%)$ cases were newly diagnosed, the interview being conducted less than a month after diagnosis.

Staff of the Federal Health Office contacted the physicians in the hospitals twice a week to investigate whether there were qualifying patients on the ward. Patients reported as being eligible were verified by the interviewers on the basis of their medical records. Of 283 patients referred, 279 qualified for the study. Twenty six patients refused to cooperate, eight could not be interviewed for organisational reasons, and in six patients no interview was carried out because of the patients' extremely poor health. This resulted in 239 cases ( $84 \%$ of all qualifying subjects).

\section{SELECTION OF CONTROIS}

Up to three German citizens matched for sex and age and living currently within the city were recruited as controls for each case. They were drawn from the population registration list (of the western sector) of the former West Berlin. Of the 635 controls contacted, 137 refused to cooperate and 17 were too sick to be interviewed. Interviews from 52 people were excluded from the analyses because of questionable and incomplete responses. Thus information from 429 controls $(67.5 \%)$ was used in the analyses.

\section{INTERVIEW}

Cases were interviewed by staff members in the hospital with a computerised questionnaire designed for the purpose on a portable lap top computer. The interviewers were especially trained to use this new instrument. The average interview time was about an hour. The control group was interviewed with the same instrument in their homes. The refusal rate was $9 \cdot 2 \%$ among the cases and $21 \cdot 5 \%$ among the controls.

Care was taken that all interviewers were trained according to the same standards. The interview consisted of questions on eight main topics: healthy lifestyle, nutrition, active and passive smoking, history of keeping pet animals, occupational exposure to lung 
carcinogens, health status, and sociodemographic factors.

A pretest was conducted comparing the computerised interview with an analogous written questionnaire. The computerised interview proved to be advantageous, requiring less time with the subject and providing better quality data. Specific filter questions and checks on the plausibility of answers during the interview ensured that all questions were answered and that the responses were properly coded. The data were stored on $3^{12 \prime}$ diskettes, which were merged daily onto a DBXL database of a Compac 386/20x personal computer.

\section{STATISTICAL ANALYSES}

We used two types of analysis to assess the relative impact of keeping pet birds on the risk of developing lung cancer. A Mantel-Haenszel stratified analysis was performed to find the effect of smoking on the odds ratio of developing lung cancer according to whether pet birds were kept. Logistic regression analyses were also conducted, ${ }^{22}$ with lung cancer as the dependent variable and risk factors and suspected confounders as independent variables. Initially, smoking status; occupational exposure; passive smoking in childhood; consumption of carrots, peppers, brussel sprouts, kohlrabi, and spinach; and the number of years of exposure to pet birds were entered additively into a conditioned logistic regression model with 239 matching sets. All variables except the intake of vegetables other than carrots contributed significantly to the model.

\section{ASSESSMENT OF INDEPENDENT VARIABLES}

Whether a subject had kept pet birds was determined from the answer to the question, "During adulthood which of the following birds did you keep, and for how long: parrot, parakeet, canary, exotic birds, or other birds?" How long pet birds had been kept was determined from the answer to: "When you were a child did you live in a house where birds were kept? If so, which birds and for how long?" In addition, subjects were asked: "As an adult, which birds did you have in your home until 1985? How long had you had them?"

Smokers were defined as people who smoked at least one cigarette a day up to 1985.1985 was chosen to allow for a latency period of at least three years before the development of the neoplasm in the cases. Pack years were calculated as the sum of the product of the number of cigarettes, cigars, or pipes smoked a day before 1985 and the number of years each of these products was smoked.

Passive smoking during childhood was considered to be present if anyone smoked regularly where the subject lived as a child. Passive smoking during adulthood was considered to be present if the sum of years of exposure from living or working where others smoked exceeded four.

The intakes of vitamin $C$ and $\beta$ carotene were assessed. Questions were asked on the frequency of consumption of oranges, grapefruit, strawberry, orange juice, grapefruit juice, acerola berry juice, and vitamin pills to assess the intake of vitamin $C$, and on the consumption of brussel sprouts, red peppers, swedes, and carrots to assess the intake of $\beta$ carotene.

Occupational exposure to pulmonary carcinogens was suspected to be present when the number of years worked in one of the following professions was more than three: waiter (passive smoking); tailor, furrier, hairdresser, joiner, asbestos worker, miner, metal worker, chemical plant employee, and carpet layer (exposure to chemicals); and lorry or bus driver, policeman, or petrol station operator (exposure to exhaust fumes). These occupations were chosen because of reports of increased lung cancer risk in epidemiological studies. ${ }^{23-26}$

Heating systems in the home and the amount of living space in the home were also assessed and analysed. Neither showed an effect on the risk of developing lung cancer and were not included in the final model.

Calculations of attributable risk were based on the 1988 standardised mortality rate for lung cancer (as defined by International Classification of Diseases code $162^{27}$ ) in the former Federal Republic of Germany. The deaths attributable to exposure to pet birds in those aged 40-65 were estimated from national mortality statistics and calculated according to the formula proposed by Schlesselman..$^{28}$ Independence of effect was assumed.

\section{Results}

Table I shows the distribution of the independent variables of interest among the 239 cases and 429 controls.

The results of matched analyses showed that after smoking had been controlled for pet birds in the household conferred on average a twofold risk for the development of lung cancer. The odds ratio was 1.92 in men and $2 \cdot 44$ in women.

The inclusion of interaction terms for all main variables with sex, to test the hypothesis of sex differences, showed no improvement of the fit for the multiple logistic regression model. Therefore, both sexes were combined in the matched logistic regression model.

The combined odds ratio for exposure to pet birds for men and women in the conditional logistic regression model amounted to $2 \cdot 14$ after adjustment for the following explanatory and confounding variables: smoking (yes/no), occupational exposure (yes/no), passive smoking during childhood (yes/no), and frequency of carrot consumption. The results can be found in table II.

The strongest factor influencing lung cancer was previous cigarette smoking (relative risk=16). Occupational exposure to hazardous substances also carried a threefold risk of lung cancer. No significant interaction between smoking and occupational exposure was found.

In addition to the well known influence of cigarette smoking, passive smoking during childhood independently contributed as a risk factor for lung cancer, although to a much smaller degree. The point estimate of the odds ratio for this factor was 1.57 , reflecting an exposure rate of $72 \cdot 8 \%$ for the cases and $53.4 \%$ for the controls.

When the duration of exposure to birds was introduced as a metric variable the relation to lung cancer

TABLE I-Distribution of variables of interest between cases and controls. Values are numbers (percentages) unless stated otherwise

\begin{tabular}{lcc}
\hline Characteristic & $\begin{array}{c}\text { Controls } \\
(\mathrm{n}=429)\end{array}$ & $\begin{array}{c}\text { Cases } \\
(\mathrm{n}=239)\end{array}$ \\
\hline Keeping pet birds: & & \\
$\quad$ No & $328(76 \cdot 4)$ & $141(59 \cdot 0)$ \\
$\quad$ Yes & $101(23 \cdot 5)$ & $98(41 \cdot 0)$ \\
Smoking: & & \\
$\quad$ Non-smoker & $193(45 \cdot 0)$ & $11(4 \cdot 6)$ \\
$\quad$ Smoker & $236(55 \cdot 0)$ & $228(95 \cdot 4)$ \\
Occupational exposure ${ }^{\star}:$ & $307(71 \cdot 6)$ & $88(38 \cdot 6)$ \\
$\quad$ No & $122(28 \cdot 4)$ & $151(63 \cdot 2)$ \\
$\quad$ Yes & $55 \cdot 2$ & $55 \cdot 3$ \\
Average age (years) & $1 \cdot 74$ & $3 \cdot 78$ \\
Average duration of keeping pet birds (years) & & \\
Passive smoking as child: & $200(46 \cdot 6)$ & $65(27 \cdot 2)$ \\
$\quad$ No & $229(53 \cdot 4)$ & $174(72 \cdot 8)$ \\
$\quad$ Yes & $333(77 \cdot 6)$ & $187(78 \cdot 2)$ \\
Sex: & $96(22 \cdot 4)$ & $52(21 \cdot 8)$ \\
$\quad$ Men & & \\
$\quad$ Women & & \\
& &
\end{tabular}


TABLE II-Effect of keeping pet birds on risk of developing lung cancer. Results of logistic regression analyses adjusted for smoking, occupation exposure to carcinogens, passive smoking as a child, and carrot consumption

\begin{tabular}{|c|c|c|c|c|c|}
\hline & $\begin{array}{l}\text { No of } \\
\text { cases }\end{array}$ & $\begin{array}{c}\text { No of } \\
\text { controls }\end{array}$ & $\begin{array}{l}\text { Adjusted } \\
\text { odds ratio }\end{array}$ & $\begin{array}{l}95 \% \text { Confidence } \\
\text { interval }\end{array}$ & $\mathrm{p}$ Value \\
\hline \multicolumn{6}{|l|}{ Pet bird keeping: } \\
\hline $\mathrm{No}^{\star}$ & 141 & 328 & 1.00 & & \\
\hline Yes & 98 & 101 & 2.14 & 1.35 to 3.40 & 0.001 \\
\hline \multicolumn{6}{|l|}{ Smoking: } \\
\hline $\mathrm{No}^{\star}$ & 11 & 193 & $1 \cdot 00$ & & \\
\hline Yes & 228 & 236 & 16.08 & $6 \cdot 82$ to $37 \cdot 36$ & 0.000 \\
\hline \multicolumn{6}{|c|}{ Occupational exposure: } \\
\hline $\mathrm{No}^{\star}$ & 88 & 307 & 1.00 & & \\
\hline Yes & 151 & 122 & 3.07 & 1.97 to 4.79 & 0.000 \\
\hline \multicolumn{6}{|c|}{ Passive smoking as child } \\
\hline $\mathrm{No}^{\star}$ & 65 & 200 & 1.00 & & \\
\hline Yes & 174 & 229 & $1 \cdot 70$ & 1.07 to 2.70 & 0.025 \\
\hline \multicolumn{6}{|l|}{ Carrot consumption: } \\
\hline Seldom, never ${ }^{\star}$ & 67 & 65 & 1.00 & & \\
\hline Trend & & & 0.74 & 0.62 to 0.88 & 0.002 \\
\hline
\end{tabular}

${ }^{\star}$ Reference category.

TABLE II-Effect of duration of keeping pet birds on risk of developing lung cancer. Results of logistic regression analyses adjusted for smoking, occupational exposure to carcinogens, passive smoking as a child, and carrot consumption

\begin{tabular}{|c|c|c|c|c|c|}
\hline & $\begin{array}{l}\text { No of } \\
\text { cases }\end{array}$ & $\begin{array}{l}\text { No of } \\
\text { controls }\end{array}$ & $\begin{array}{c}\text { Adjusted } \\
\text { odds ratio }\end{array}$ & $\begin{array}{l}95 \% \text { Confidence } \\
\text { interval }\end{array}$ & p Value \\
\hline \multicolumn{6}{|c|}{ Duration of pet bird keeping (years): } \\
\hline None* & 141 & 328 & $1 \cdot 00$ & & \\
\hline $1-5$ & 51 & 49 & $2 \cdot 63$ & 1.79 to 3.20 & 0.001 \\
\hline $6-10$ & 20 & 40 & $1 \cdot 20$ & 0.57 to 2.53 & 0.626 \\
\hline$\geqslant 11$ & 27 & 12 & $3 \cdot 10$ & 1.48 to 8.21 & 0.021 \\
\hline \multicolumn{6}{|l|}{ Smoking: } \\
\hline $\mathrm{No}^{\star}$ & 11 & 193 & $1 \cdot 00$ & & \\
\hline Yes & 228 & 236 & $16 \cdot 40$ & 6.90 to 38.42 & 0.000 \\
\hline \multicolumn{6}{|l|}{ Occupational exposure: } \\
\hline $\mathrm{No}^{\star}$ & 88 & 307 & $1 \cdot 00$ & & \\
\hline Yes & 151 & 122 & 3.01 & 1.93 to 4.72 & 0.000 \\
\hline \multicolumn{6}{|c|}{ Passive smoking as child: } \\
\hline $\mathrm{No}^{\star}$ & 65 & 200 & 1.00 & & \\
\hline Yes & 174 & 229 & 1.59 & 0.98 to 2.56 & 0.050 \\
\hline \multicolumn{6}{|l|}{ Carrot consumption: } \\
\hline Seldom or never* & 67 & 65 & $1 \cdot 00$ & & \\
\hline$\geqslant$ Once in month & 103 & 169 & $0 \cdot 82$ & 0.47 to 1.44 & 0.484 \\
\hline$\geqslant$ Once in week & 65 & 172 & $0 \cdot 40$ & 0.22 to 0.77 & 0.007 \\
\hline Daily & 4 & 23 & $0 \cdot 24$ & 0.07 to 0.86 & 0.029 \\
\hline
\end{tabular}

${ }^{\star}$ Reference category.

\section{Discussion}

The aim of the study was to discover whether keeping pet birds is an independent risk factor for developing lung cancer. The question was triggered by previous research. ${ }^{7}$ The results clearly indicate that there is a more than twofold risk for developing lung cancer if people are exposed to pet birds in the household. This risk remained stable throughout all analyses, from $2 \times 2 \times 2$ contingency table calculations according to Mantel-Haenszel to multivariate conditional logistic regression models that include more than 10 independent variables. Moreover, a dose-response relation was found showing increased risks per year of pet bird keeping. The subgroup analysis showed an odds ratio of 2.6 for $1-5$ years of exposure to birds and $3 \cdot 1$ for more than 10 years. The non-significant difference in the exposure group with 6-10 years of contact with birds cannot be explained. It may be a problem of measurement error, with few people accurately being able to estimate yearly exposure, or the lack of power for subgroup analyses with only 20 cases.

Although the pathogenic relation between lung cancer and exposure to birds is not known, at least two plausible pathways exist. The relation may be either mycological or an association with inhaling particulate matter such as feather fragments from the birds.

The response of alveolar macrophages to particulate matter in the periphery of the lung is known (N Konietzko, international symposium on pneumoconioses, Shenyang, China, 1988). An influx of granulocytes and lymphocytes into the resident lung cell can be induced by mediators such as enzyme proteases released from the macrophages. Suppressor $T$ lymphocytes are also increased, resulting in extrinsic allergic alveolitis. Furthermore, alveolar macrophages stimulate the proliferation of fibroblasts and the deposition of collagen into the extracellular matrix, which result in fibrosis. That pneumoconiosis can be related to lung cancer has been shown in a Japanese cohort of 3335 hospital patients with pneumoconiosis in a nested case-control study design; the odds ratio for the development of lung cancer given the presence of pneumoconiosis was 4.8 (K Chiyotani and K Saito, international symposium on pneumoconioses, Shenyang, China, 1988).

Although seldom related to lung cancer, contact with birds carries risk to various organ systems, including the respiratory tract. Mycoses that may be detrimental include Cryptococcus neoformans (with its sexual form as Filobasidiella neoformans), which is cultivated in the faecal products of pet birds, and, when inhaled, can cause a primary lung infection to develop into systemic cryptococcosis affecting all organ systems, including the central nervous system. This has been documented in bird fanciers and exposed AIDS patients. ${ }^{30-32}$ Aspergilli and mucoraceae grow not only in compost and the soil of potted plants but in bird droppings mixed with the vegetable matter of bird feed. ${ }^{33-35}$ Their inhalable spores are known to endanger the lung and bronchial tract of immunodeficient people. ${ }^{34}$

Published work on diseases related to avian contact, such as pigeon fanciers' disease, has not yet found the causal mechanism. ${ }^{36} 37$ Thus, although acute clinical symptoms are apparent in immunodeficient subjects, the potential risk in the general population from these different fungi at the exposure levels associated with bird keeping is unknown.

This study was conducted in collaboration with Professors D Kaiser, R Loddenkemper, and $\mathrm{H}$ Lode and Dr I Broll of Heckeshorn Chest Hospital, Berlin, and Professor D Krumhaar of Havelhoehe Hospital, Berlin. and that the relative risk for keeping pet birds is $2-$ mean that 15 of the 88 lung cancer fatalities per 100000 males and three of the 15 per 100000 females are attributable to avian contact.

was also evident but with a lower risk (relative risk
$1 \cdot 4$ ). After the duration of keeping birds was classified into four categories (never, $1-5$ years, $5-10$ years, more
than 10 years) the risk of developing lung cancer was more than twice as high in people reporting one to five years of exposure compared with those reporting no 10 years compared with no avian contact in the significant differences in age between people longer exposures to birds and people with shorter One of the nutritional variables assessed in the study with regularly eating carrots indicated that highe 0.44 , and 0.23 compared with the values in people who model can be seen in table III

The attributable risk estimates ${ }^{29}$-assuming that $20 \%$ of the general population keep birds in their households (random survey in 1989 of 2744 people) 
1 Axelson O, Davis DL, Forestiere F, Schneidermann M, Wagener D. Lung cancer not attributable to smoking. In: Davis DL, Hoel DG, eds. Trends in cancer mortality in industrial colntries. New York: New York Academy of Sciences, $1990 \cdot 165-78$

2 Carstensen JM, Axelson $\mathrm{O}$. Changes in non-smoking related lung cancer with special reference to mortality trends in Swedish women. In: Davis DI. Hoc DG, eds. Trends in cancer mortality in indistrial countries. New York: New York Academy of Sciences, 1990:159-64

3 National Research Council. Health risks of radon and other internally deposited alpha-emitters: BEIR IV. Washington, DC: National Academy Press, 198

4 National Research Council. Environmental tobacio smoke: measuring exposurs and assessing health effects. Washington, DC: National Academy Press, 1986.

National Research Council. Abestiform fibers: nonoccupational health risks. Washington, DC: National Academy Press, 1984.

6 Rosenstock L, Cullen MR. Clinical occupational medicine. Philadelphia: Saunders, 1986.

7 Holst PA, Kromhout D, Brand R. For debate: pet birds as an independent risk factor for lung cancer. $B M 7$ 1988;297:1319-21.

8 Reed CE, Sosman A, Barbee RA. Pigeon breeders' lung. FAMA 1965;193: $261-5$

9 Fink JN. Sosman AJ, Barboriak JJ, Schlueter DP, Holmes RA. Pigeon breeders' disease: a clinical study of hypersentivity pneumonitis. Ann Intern Med 1968;68:1205-19.

10 Bourke SJ, Carter R, Anderson K, Boyd J, King S, Douglas B, Boyd G. Obstructive airways disease in non-smoking subjects with pigeon fanciers' lung. Clin Exp Allergy 1989;19:629-32.

11 Balasubramaniam SK, O'Connel EJ, Yunginger JW, McDugall JC, Sachs MI Hypersensitivity pneumonitis due to dove antigens in an adolescen Clin Pediatr (Phila) 1987;26:174-6.

12 Grammer LC, Roberts M, Lerner C, Patterson R. Clinical and serologic follow-up of four children and five adults with bird-fanciers' lung. F Allerg Clin Immunol 1990:85:655-60.

13 Ostergaard JR. Reversible pulmonary arterial hypertension in a 6-year-old girl with extrinsic allergic alveolitis. Acta Paediatr Scand 1989;78:145-8.

14 Schlueter DP, Fink N, Sosman AJ. Pulmonary function in pigeon breeders' disease: hypersensitivity pneumonitis. Ann Intem Med 1969;70:457-70.

15 Allen KH, Williams GV, Woolcock AJ. Bird breeders' hypersensitivity pneumonitis: progress studies of lung function after cessation of exposure to the provoking antigen. Am Rev Respir Dis 1976;114:555-66.

16 Hagmar L, Schuetz A, Sjoeholm A. Over-shift decrease in lung function in poultry slaughterhouse workers. Am f Ind Med 1990;17:77-8.

17 Schmidt CDW, Jensen RL, Christensen LT, Crapo RO, Davis JJ. Longitudinal pulmonary function changes in pigeon breeders. Chest 1988;93:359-63

18 Keller RH, Swartz S, Schlueter DP, Bar-Sela S, Fink JN. Immunoregulation in hypersensitivity pneumonitis: phenotypic and functional studies of bronchoalveolar lavage lymphocytes. Am Rev, Respir Dis 1984;130: $766-71$

19 Smith JH, Neill PJ, Dillard EA III, Box ED. Pathology of experimental Sarcoscystis falcatula infections of canaries (Serinus canarius) and pigeons (Columba livia) f Parasitol 1990;76:59-68.

20 Bourke SJ, Banham SW, McKillop JH, Boyd G. Clearance of $99 \mathrm{~m}$ Tc-DTPA in pigeon fanciers hypersensitivity pneumonitis. Am Rev Respir Dis 1990;142:1168-7

21 Bundesminister für Jugend, Familie und Gesundheit Internationale Klassifikation der Krankheiten, Verletzungen und Todesursachen (ICD). Cologne: Kohlhammer, 1988.

22 Statistics and Epidemiology Research Corporation and Cytel Software Corporation. EGRET. Seattle, Washington: SERC, 1991:1-116.

23 Fehr R, Funke U, Kollmeier H, Krasemann EO, Weißker J. Berufsspezifische Krebsrisiken, untersucht anhand des Hamburger Krebsregisters. Hamburger Krebsdokumentation 1978 und 1979. Hamburg: Statistik des Hamburgischen Staates, 1983:137

24 Menck HR, Henderson BE. Occupational differences in rates of lung cancer. 7 Occup Med 1976;18:797-801.

25 Milne KL, Sandler DP, Everson RB, Brown SM. Lung cancer and occupation in Alameda County. A death certificate case-control study. Am 7 Ind Med 1983;4:565-75.

26 Pukkala E, Teppo L, Hakulinen T, Rimpelä M. Occupation and smoking as risk determinants of lung cancer. Int $\mathcal{F}$ Epidemiol 1983;12:290-6.

27 Statistisches Bundesamt. Gesundheitswesen. Fachserie 12. Reihe 4 Todesursachen 1988. Stuttgart: Metzler-Poeschel, 1989.

28 Schlesselman JJ. Case-control studies: design, conduct, analysis. New York: Oxford University Press, 1982

29 Walter S. The estimation and interpretation of attributable risk in health research. Biometrics 1976;32:829-49.

30 Wegener HH, Staib F. Tödliche Cryptococcose eines Vogelliebhabers--Ein kasuistischer Beitrag zur Pathologie, Diagnostik und Epidemiologie der Cryptococcose. Zentralblatt Bakteriologie und Hygiene 1983;256:231-8.

31 Staib F, Seibold M, Antweiler E, Fröhlich B, Heißenhuber M, Voigt R, et al. Cryptococcus neoformans bei Patienten einer Berliner Lungenklinik--Ein Beitrag zur Diagnostik und Bekämpfung der Cr. neoformans-Mykose. Praxis und Klinik der Pneumonologie 1986;40:86-93.

32 Staib F. Kryptokokkose bei AIDS aus mykologisch diagnostischer und -epidemiologischer Sicht. AIDS-Forschung 1987;2:363-82.

33 Staib F. Sampling and isolation of Cryptococcus neoformans from indoor air with the aid of the Reuter Centrifugal Sampler (RCS) and Guizotia abysinica creatinine agar. A contribution to the mycologicalabyssinica creatinine agar. A contribution to the mycologicalepidemiological control of $C r$ neoformans in the fecal

34 Staib F, Seibold M, Heißenhuber M. Indoor air mycology-aspergillosis, mucormycosis and cryptococcosis caused by fungal spores from indoor air In: Indoor air '87. Vol 1. Berlin: Institute for Water, Soil and Air Hygiene, 1987:694-8.

35 Staib F, Heißenhuber M. Cryptococcus neoformans in bird droppings: hygienic-epidemiological challenge. AIDS-Forschung 1989; 4: 649-55.

36 Staib F, Bethäuser G. Zum Nachweis von Cryptococcus neoformans im Staub von einem Taubenschlag. Mykosen 1968;11:619-24.

37 James JM, Brouet JC, Orvoenfrija E, Capron F, Brechot J, Danon F, et al. Waldenström's macroglobulinaemia in a bird breeder: a case history with pulmonary involvement and antibody activity of the monocional IgM to canary's droppings. Clin Exp Immunol 1987;68:397-401.

(Accepted 1 fune 1992)

\section{Avian exposure and bronchogenic carcinoma}

\section{Austen J S Gardiner, Barbara A Forey, Peter N Lee}

\section{Abstract}

Objective-To investigate the association between bird keeping and risk of lung cancer.

Design-Case-control study asking detailed questions on exposure to domestic birds and other pets, smoking, and various demographic and potentially confounding variables.

Setting-District general hospital; current admissions interviewed in hospital or recent admissions interviewed at home.

Patients-143 patients with lung cancer, 143 controls with heart disease, and 143 controls with orthopaedic conditions individually matched for age, sex, date of admission, and current or past admission.

Main outcome measures-Odds ratios for lung cancer in relation to various aspects of bird keeping, after adjustment for smoking and other relevant confounding variables.

Results-Risk of lung cancer was not significantly associated with household exposure to pet birds at any time or at various specific periods in life, or to keeping large numbers of birds. For specific types of birds no association was seen for living in households with budgerigars or canaries but risk was significantly associated with keeping pigeons (odds ratio 3.53, $95 \%$ confidence interval 1.56 to 7.98 ). This remained significant after regression analysis to account for confounding variables $(3.9,1.2$ to 12.62$)$ in both sexes and all age groups.
Conclusion-Bird keeping may confer some risk of lung cancer but the relation is not as strong as previously reported.

\section{Introduction}

In 1988 Holst et al described results of studies suggesting a strong relation between bird keeping and risk of lung cancer. ${ }^{12}$ An early study in his general practice in the Netherlands found that newly diagnosed malignant tumours in patients aged 30 or more were more common in those who had kept pet birds five to 14 years before diagnosis than in those who had not. Of 12 lung tumours seen, seven were in bird keepers; the expected number was $3.2(p<0 \cdot 05)$. After a small study showing a clear relation between the concentration of suspended particles of $3 \mu \mathrm{g}$ diameter or more and presence of birds in the home, Holst conducted a case-control study in four hospitals in the Hague studying 49 patients with lung cancer and 98 age and sex matched controls from general practice. After adjustment for confounding variables, bird keepers were found to have a 6.7 times increased risk of lung cancer $(95 \%$ confidence interval $2 \cdot 2$ to 20$)$. The increase was similar for keepers of all types of birds and all histological types of lung cancer.

The Netherlands has a high rate of lung cancer and bird keeping, and Holst estimated that had no one in the Hague kept birds the total incidence of lung cancer would have been almost three times lower. He recom- 